\title{
A Discussion on the Naming of Mass Rapid Transit Systems: Metros in Taiwan
}

\author{
Ya-Lan Tang \\ Department of English, Tamkang University, Taiwan \\ Email: cylt206@gmail.com
}

How to cite this paper: Tang, Y.-L. (2016). A Discussion on the Naming of Mass Rapid Transit Systems: Metros in Taiwan. Open Journal of Modern Linguistics, 6, 420427.

http://dx.doi.org/10.4236/ojml.2016.65037

Received: September 13, 2016

Accepted: October 23, 2016

Published: October 26, 2016

Copyright $\odot 2016$ by author and Scientific Research Publishing Inc. This work is licensed under the Creative Commons Attribution-NonCommercial International License (CC BY-NC 4.0). http://creativecommons.org/licenses/by-nc/4.0/ c.) (i) \& Open Access

\begin{abstract}
Mass Rapid Transit systems are a fast and efficient way of transportation when visiting cities around the world. Although it is generally recognized that words such as metro or subway would direct tourists to the nearest station, the words have only a limited use in Taiwan. This research shows that the Taiwanese are more used to the term MRT, which is not easily recognized by foreigners. By looking into etymology and investigating the academic wordlists and news reports, it is found that tourists in Taiwan might have a problem communicating their intention of getting direction to a metro station. The same is true for the Taiwanese people on tour to other countries-they will have a hard time finding the metro station by asking for the MRT station. The research suggests that the government should strongly consider properly naming the metro systems in Taiwan and to educate the youngsters in Taiwan on the usage of the words metro and subway.
\end{abstract}

\section{Keywords}

Metro, Subway, Translation, Language and Culture

\section{Introduction}

Mass Rapid Transit (MRT) systems are an important mode of transportation in modern cities. Currently, there are two MRT systems operating in Taiwan-one in Taipei, the capital of Taiwan; and the other in Kaohsiung, the second largest city located in the south. The systems have been named at the onset, the Taipei MRT and the Kaohsiung MRT, respectively. Contrary to the norm in English-speaking countries, where the term "MRT" is rarely used in daily communications, both verbal and written; MRT is a common term that is used extensively in Taiwan. The information from the Taipei MRT website posts ambiguity in the history of the system. For one, it is stated that the “Taipei Metropolitan Rapid Transit Systems" was approved by the government in 1986 
while the "Taipei Rapid Transit Corporation" was incorporated in 1994. Both of the names refer to the system as the Taipei MRT. However, the current logo of the company and the system is "Metro Taipei" while in press releases, it is termed "Taipei Metro." Such confusion should not have happened in the public sector.

Halcrow Group (2000:S2) in the report to the World Bank defines four generic forms of mass transit that currently exist in major cities:

1. Busways-these are generally segregated sections of roadway within major corridors, with horizontal protection from other traffic, and priority over other traffic at junctions, which are generally signalized.

2. Light rail transit (LRT) - this is at-grade, with similar horizontal protection to busways.

3. Metros-these are fully segregated, usually elevated or underground. It is the segregation that is critical to providing a rapid service, and the technology that allows a high mass ridership to be carried.

4. Suburban rail-these services are usually physically part of a larger rail network, usually at-grade and fully-segregated incorporating road-rail segregation or controlled level-crossings.

Although four generic forms of mass transit are defined, such systems in Taiwan are generally promoted and misleadingly explained both in the public and private sectors of tourism as "MRT". Below is a sample introduction to the systems used in Taiwan.

“Mass Rapid Transit System also named 'Metro' or 'Subway'. The Mass Rapid Transit System is a public transportation system, using electric-powered rolling stock running in its own right-of-way on guideway facilities at-grade, underground, or elevated, free from interference with other ground traffic, to transport large volumes of passengers at high speeds and with short headway, in the city and its adjacent areas." (Virtual Asia.com, 2016; Mass Rapid Transit Bureau of Kaohsiung City, 2016)

This research mainly aims to look into the wide-spread usage of the term "MRT" in Taiwan and to promote the usage of the term "metro" in the place of "MRT". Dictionary definitions and etymology are the starting point of research. Moreover, data is collected from various sources in Taiwan including wordlists, news reports, and test papers administered in Taiwan to show the usage of words in Taiwan. The names of the metro systems around the world will also be analyzed to support the claim the mass rapid transit systems in modern cities are better named metro or subway. Results will be discussed with suggestions to follow.

\section{Literature Review}

The study of language and culture has sprouted many books and papers and it is generally believed that language and culture are closely related to each other in a bilateral way. On the one hand, language is the carrier and container of culture. This means as human being interact with the surrounding world, the experience-all components of culture, such as beliefs, customs, arts, techniques, and others-can be described, ana- 
lyzed and evaluated by language. Such experience is stored and transmitted by language as well. On the other hand, language is influenced and shaped by culture-language is a mirror of culture. As the interaction between the two is intertwined, the understanding of one requires understanding of the other. Finally, the emergence and development of language and culture are simultaneous and spontaneous in human history (Liu, 2013; Yu, 2013; Zhan \& Dong, 2010; Risager, 2006; Kramsch, 1998; Graddol et. al., 1993).

Aside from language and culture, when two cultures interact, the need for translation is paramount. Overview of the translation in China have been presented in countless books and they all point to the importance of "maintaining truthfulness and semantical correctness in translation" (Chen, 1992; Huang, 1988; Di \& Nida, 1984). Although Newmark's "A Textbook of Translation" (1988) has been the standard reference book in use for Taiwanese students, as the example in introduction exemplifies, the choice of words in translating the metro system in Taipei to Taipei MRT was a poor one. It has not taken into accounts of how the target language (in this case, English) is being used; and thus resulting in confusion.

Ambiguity in translation of the Taipei metro have been documented through analyses of travel related publications such as tourist information brochures and travel guides. Tian (2015) researched the translation of the official "Taipei MRT Guide" and reported the level of acceptance by Spanish-speakers. On the other hand, Teng (2011) looked at the MRT Guide in respect to Japanese users. Aside from these, a simple Google Scholar search renders slight more results for "Taipei MRT" than "Taipei metro" $-15,000$ versus about 12,000. The results illustrates the widespread of the term MRT being used in Taiwan.

\section{Method}

The research design follows the scheme of first defining the terms in question, then looking at their presence in academic wordlists and news reports to establish a relative frame of usage in Taiwan. Finally, the naming of the mass rapid transit systems will be analyzed. By comparative analysis, the most logical and clearest way to refer to such systems are determined and reported.

We begin the research from linguistic etymology point of view. Harper's (2016) Online Etymology Dictionary defines the words as:

- Metro-Paris underground, dates back to 1904, from French abbreviation of Chemin de Fer Métropolitain, meaning "Metropolitan Railway". Literally, it is translated to Metropolitan iron road.

- Subway-originally meaning "underground passage" dating back to 1825 . Usage of "underground railway in a city" was first recorded in 1892 in reference to London.

It is interesting to note that the search for "MRT" and "Rapid Transit" would render no results from Harper's dictionary. The only terms that relate to metro systems are U-Bahn, a German term that refers to the German or Austrian subway system; and Tube, the famous London subway system. Furthermore, the term "underground" used as a noun is generally regarded as being related to transportation in the USA that dates 
back to 1887 as a shortened form of "underground railway". This gives us that first clue to the naming of mass rapid transit system.

Aside from etymology, dictionaries are consulted to provide definitions to the terms under research. Merriam-Webster's Learner's Dictionary defines metro as an underground railway system in some cities, equivalent of subway. Moreover, Oxford Advanced Learner's Dictionary gives the definition as an underground train system, especially the one in Paris. Cambridge Advanced Learner's Dictionary \& Thesaurus defines metro as "a railway system that runs under the ground below a city". Finally, Longman Dictionary of Contemporary English states that metro is an underground, or largely underground, railway system in certain cities, especially in Europe, such as that in Paris. Dictionary definition searches exhibit the following similarities:

1. Metro is an underground train system;

2. such systems are mostly found in cities; and

3. the first metro system is that in Paris.

As Taiwan's education is closely governed by the Ministry of Education and advancement to higher education is mostly based on test scores; for the present research, in order for the researcher to gather a full extent of the terms used in Taiwan, three official wordlist sources will be used-one by the Ministry of Education; another from the mainstream English proficiency test, and the other from the College Entrance Examination Center. Terms under research include metro, MRT, subway, underground, and tube. The result will demonstrate the how the government views the selected words and how the ideology is passed onto the students in Taiwan by form of formal education and testing.

The General Guidelines of Grade 1 - 9 Curriculum of Elementary and Junior High School Education, which is under the administration of the Ministry of Education in Taiwan, stipulates two specific wordlists-one with 1200 words is suggested to be used by students up to grade 6; and the other with 2000 words (including the aforementioned 1200) meant for grades 7 through 9 students. Only three of words under research are included in the wordlists-MRT, subway, and tube; as listed below (Table 1).

The implication of such is that first, "tube" is not related to transportation like "MRT" and "subway" are. Secondly, the word "metro" is not found. This means that the Ministry of Education in Taiwan considers metro as a "basic" English word that students, up to grade 9, need to acquire for everyday purposes.

The General English Proficiency Test (GEPT) is the key test of English ability administered in Taiwan. Wordlists for each level of the test is provided as a study guide to test-takers. The words under research found in the wordlist are listed in Table 2. It is

Table 1. Words under research found in the Ministry of Education Wordlist.

\begin{tabular}{cccc}
\hline Word & Part of Speech & Notes & Level \\
\hline MRT & noun & transportation & 1200 wordlist \\
Subway & noun & transportation & 2000 wordlist \\
tube & noun & houses and apartments & 2000 wordlist \\
\hline
\end{tabular}


Table 2. Words under research found in the GEPT Wordlist

\begin{tabular}{|c|c|c|c|}
\hline Word & Part of Speech & Notes & Level \\
\hline metro & noun & $=$ Metro & intermediate level \\
\hline MRT & noun & $\begin{array}{c}=\text { mass rapid transit } \\
=\text { subway } \\
=\text { underground } \\
=\text { metro }\end{array}$ & elementary level \\
\hline subway & noun & $\begin{array}{c}\text { =underground } \\
\text { =tube (British English) } \\
=\text { MRT } \\
=\text { metro }\end{array}$ & elementary level \\
\hline underground & adj./adv./noun & & intermediate level \\
\hline tube & noun & $=$ underground railway & intermediate level \\
\hline
\end{tabular}

found that MRT and Subway are deemed as the equivalent of the word "metro." However, the reverse is not true; that is, the word metro cannot be used to replace MRT or subway.

Below is a sample question from the GEPT test that uses "MRT," taking straight from the testing center that uses the word "MRT" as part of the question".

How can I get to the MRT entrance?
$\begin{array}{ll}\text { Go straight ahead and take } \\ \text { the first left. You'll see it on } \\ \text { the left. } \\ \text { Go straight ahead and take } \\ \text { the first right. You'll see it } \\ \text { on the right. } \\ \text { Go straight ahead and take } \\ \text { the second left. You'll see it } \\ \text { on the left. } \\ \text { Go straight ahead and take } \\ \text { the second right. You'll see } \\ \text { it on the right. }\end{array}$
B.
D.

In terms of higher education, the College Entrance Examination is the primary exam high school graduates take to apply for colleges in Taiwan. The wordlist provided by the testing center includes 8000 words divided into 6 levels. The higher the level, the more difficult and rarer are the words. Again, a search for the words rendered the results in Table 3.

The results is interesting in that the word "metro" is not listed as headword. It is only found as being an equivalent of the word MRT. Comparative results will be presented in a latter section of the research. An example of the usage of MRT is found in the first question of the 2008 college entrance exam ${ }^{2}$.

1. The new stadium was built at a convenient , close to an MRT station and within walking distance to a popular shopping center.

${ }^{1}$ https://www.lttc.ntu.edu.tw/teacher/Reading/medium/L1S.htm ${ }^{2}$ http://www.ceec.edu.tw/AppointExam/AppointExamPaper/97DRSE_Paper/02-97drse.pdf 
Table 3. Words under research found in the College Entrance Exam Wordlist.

\begin{tabular}{|c|c|c|c|}
\hline Word & Part of Speech & Notes & Level \\
\hline metro & N/A & N/A & N/A \\
\hline MRT & noun & $\begin{array}{c}=\text { mass rapid transit } \\
=\text { subway } \\
=\text { underground } \\
=\text { metro }\end{array}$ & level 2 \\
\hline subway & noun & & level 2 \\
\hline underground & N/A & N/A & N/A \\
\hline tube & noun & & level 2 \\
\hline
\end{tabular}

(A). vacancy (B). procedure (C). residence (D). location

Aside from the dictionaries and educational materials, news reports in Taiwan systematically refer to the metro systems as MRT. For instance, the Public Television System in August 2016 reports that "Airport MRT Safe to Operate after Final Inspection" Taipei Times (August 31,2016) reports " $A$ machine at MRT Taipei City Hall Station's Exit 2, decorated with a family of cartoon bears and a large heart, allows commuters on the city's metro rail system to make NT\$50 donations and provides receipts" ${ }^{4}$. China Post writes on May 11, 2016: "MRT Killing Spree Murderer Executed". Finally, the Straits Times reports on November 13, 2015 that "Man arrested for abusing foreigner and girlfriend on MRT in Taiwan". It is intriguing to see that few reports use "metro" to refer to the mass rapid systems in Taiwan.

\section{Results and Discussion}

The first result to be discussed would be the inclusion of the word "metro" in the wordlists. As we have seen, metro is commonly used in English to refer to mass transit systems. Its usage is widely accepted without any ambiguity. However, according to wordlists in Taiwan, its presence is less than that of "MRT". For instance, it is not found in the Ministry of Education wordlist as a basic word. Moreover, it is also not listed in the College Entrance Exam wordlist; although this list is regarded in Taiwan as the "bible" for all the English words a college graduate would need to acquire.

Secondly, this misconception of using MRT over metro has been transmitted to the mass media and almost all agencies, both public and private, are inclined to use MRT in reporting. Writings in brochures and news reports tend to report Taipei Metro as Taipei MRT. This is done regardless of the official name having been changed to Taipei Metro. This ambiguity is also found in the official Taipei metro guide.

Thirdly, on the analysis of the metro systems around the world, of all the 166 mass rapid transit systems in 154 cities of 55 countries, 115 used "metro" in the name. That

${ }^{3}$ http://news.pts.org.tw/article/333054

${ }^{4}$ http://www.taipeitimes.com/News/taiwan/archives/2016/08/31/2003654231

${ }^{5} \mathrm{http}: / /$ www.chinapost.com.tw/taiwan/national/national-news/2016/05/11/465806/MRT-killing.htm

${ }^{6} \mathrm{http} / / /$ www.straitstimes.com/asia/east-asia/man-arrested-for-abusing-foreigner-and-girlfriend-on-mrt-in-tai $\underline{\text { wan }}$ 
equates to $70 \%$ of the systems worldwide name the systems as the City Name Metro. Of the exceptions, 16 of the systems, including Toronto Canada, Beijing China, and several systems in Japan, use the name of "subway". Including those "railway" systems, over $80 \%$ of the mass rapid transit systems in the world are named metro, subway, or railway. There is a strong indication that mass rapid transit systems should be better named either using the norm of City Metro or City Subway.

The results would support the following suggestions:

1. Definitions suggest that MRT is a generic term and does not constitute as a naming lexis.

2. MRT should not be part of the name for such systems. It should only be used to refer to the mechanical system.

3. MRT is not generally recognized and used in daily English communications, be it verbal or written. At such, it is not found in travel-related literature in Englishspeaking countries. However, it is widely used in Taiwan and this should be changed.

4. The role of language and culture, especially semantically, is important in the determination of how a term should be used in the target language.

5. The two metro systems in Taiwan should be named "Taipei Metro" and "Kaohsiung Metro" and the naming of future systems of such in Taiwan should follow the same principle.

\section{References}

Chen, F. G. (1992). A History of Chinese Translation Theories. Shanghai: Shanghai Foreign Languages Press.

Di, J., \& Nida, E. (1984). On Translation. Shanghai: Foreign Languages Press.

Graddol, D., Thompson, L., \& Byram, M. (Eds.). (1993). Language and Culture. Clevedon: Multilingual Matters.

Halcrow Group (2000). World Bank Urban Transport Strategy Review-Mass Rapid Transit in Developing Countries. London: Halcrow Group.

Harper, D. (2016). Online Etymology Dictionary. www.etymonline.com

Huang, L. (1988). Translatology. Jiangsu: Educational Publishing House.

Kramsch, C. J. (1998). Language and Culture. Oxford: Oxford University Press.

Liu, K. (2013). The Culture Study in Foreign Language Education. International Review of Social Sciences and Humanities, 6, 196-204.

Mass Rapid Transit Bureau of Kaohsiung City (2016). Welcome to Mass Rapid Transit Bureau, Kaohsiung City. http://mtbu.kcg.gov.tw/english/intro.php

Newmark, P. (1988) A Textbook of Translation. UK: Prentice Hall.

Risager, K. (2006). Language and Culture: Global Flows and Local Complexity. Clevedon: Multilingual Matters.

Teng, C. Y. (2011). A Study of Translation of Taipei City Travel. Kaohsiung: National Kaohsiung First University of Science and Technology.

Tian, X. (2015). Análisis de la Traducción a la Vista en el Ámbito Jurídico Castellano-Chino y la Aplicación de la Lingüística Forense. FITISPos International Journal, 2, 206-219. 
Virtual Asia.com (2016). Taiwan Transportation. http://www.virtual-asia.com/taiwan/travelpack/transport.htm

Yu, J. (2013). Cultural Awareness in Chinese-English Translation. Theory and Practice in Language Studies, 3, 2322-2326. http://dx.doi.org/10.4304/tpls.3.12.2322-2326

Zhan, J., \& Dong, Z. (2010). On Translation of Advertisements from the Perspective of Culture. Cross-Cultural Communication, 6, 117-121.

Submit or recommend next manuscript to SCIRP and we will provide best service for you:

Accepting pre-submission inquiries through Email, Facebook, LinkedIn, Twitter, etc.

A wide selection of journals (inclusive of 9 subjects, more than 200 journals)

Providing 24-hour high-quality service

User-friendly online submission system

Fair and swift peer-review system

Efficient typesetting and proofreading procedure

Display of the result of downloads and visits, as well as the number of cited articles

Maximum dissemination of your research work

Submit your manuscript at: http://papersubmission.scirp.org/

Or contact ojml@scirp.org 